\title{
Comparative Cognitive Corporate Culture Modeling of the Kabardino-Balkaria Republic's Enterprises Recreational Sphere
}

Anzor Hasanbiyevich Karanashev ${ }^{1}$

Aksana Georgiyevna Karasheva1

Leyla Borisovna Baysultanova ${ }^{1}$

\author{
Larisa Anatolyevna Tselykh²
}

Elena Anatolyevna Panfilova ${ }^{3}$

\author{
${ }^{1}$ Kabardino-Balkarian State University of H.M. Berbekov \\ ${ }^{2}$ Taganrog Institute of name A.P. Chekhov (Branch) of the Rostov State Economic University \\ ${ }^{3}$ Rostov State Economic University (RINH) \\ E-mail: karasheva05@inbox.ru
}

Doi:10.5901/mjss.2015.v6n3s4p37

\begin{abstract}
In this article are considered questions of modelling innovation potential of the corporate culture of the enterprises recreational sphere of Kabardino-Balkaria Republic based on factors of influence in the context of structural decomposition of its basic elements, taking into account aspects of Russian mentality and specificity of internal and external mechanisms of corporate development. In modelling process used method of consecutive expansion of field extension by creation of cognitive maps for three models with factors-concepts identification reflecting the specifics of the industry direction (tourist sector), the national aspect (Kabardino-Balkaria) and strategic direction of the analysis. The comparative analysis in this article shows cognitive cognitive-evolutionary aspect of the formation of the innovative capacity of a corporate culture based on the boundaries of time and space (the innovative capacity of the organization), allows you to get a better idea about the design of the system (a set of concepts, factors) to achieve the goal of innovative development.
\end{abstract}

Keywords: innovation potential, corporate culture, recreational sphere, cognitive modelling.

\section{Introduction}

The constancy of the innovative changes in the Russian economy becomes a priority process of market development of economic systems and promotes the creation of the competitive mechanism of the innovation activity. The degree of readiness of the problem is expressed in the field of farming and managing of the innovation potential of corporate culture economic practice advances the economic theory. In particular, managerial models of transition to market type of functioning of the innovation sphere are insufficiently developed, the principles of management of the innovation potential of the corporate culture of the enterprises of the recreational sphere of Kabardino-Balkaria Republic is poorly studied.

Market reforms have extended new factor forming and functioning innovation potential of the corporation as a cooperative culture. The variety of approaches to research of the innovation potential, is explained by that the majority of works on this perspective have functional and industry character, remaining within the developed economic specialization of strategic and financial management, business planning, engineering, marketing, logistics, etc. Within these directions the sufficient analytical tools for assessment of the innovation opportunities of cooperation in different fields of activity are saved up; at the same time, the complex character of the innovation potential of the corporate culture of the enterprises of the recreation sector of Kabardino-Balkaria Republic demands system approach, special development of methodical aspects of measurement and forming of the innovation potential.

Implementation of the innovation potential gives to the organization competitive advantages is the basis of forming of increase in the income, profits and in, whole, its successful development. However, the problem is one-time (single) manifestation of this essence. Some companies can show prompt take-off due to the innovation only once and then slowly die away, become averages, live at the expense of the purchased development impulse once. Achievement of permanent generation and implementation of innovations in the work of the organization is the main goal of the innovative 
enterprise in knowledge of the oriented economy.

Source of preserving, forming and stable growth of potential is a development of the innovation, corporate culture of the organization which gives direct impulses for innovations, does not allow to stiffen in the development. Successfully developing a corporate culture becomes the self-amplifying ecological environment, peculiar internal infrastructure of innovations which in total increases the potential for productive innovation changes in all spheres of the organization. At the same time, the low culture can become an obstacle for innovations since will not create incentives, desires, and motivations for changes, will keep the existing behavior, procedures, and precisians.

The concept of organization, corporate culture was created and has gained the development in the works of the American scientists (E. Shan, P. Druker, T. Dial, A. Kennedy, R. Kilmann, etc.). Contrary to the American concept of organization, corporate culture, supporters of cross-cultural approach (D. Chayld, N. Adler, G. Hofsted, P. Lewis) to maintaining corporate entrepreneurship proclaims cultural determinism which defines the importance of the cultural differences in the micro institutional level setting value system, regulations, views and types of organizational behavior.In domestic economic science the corporate culture was investigated in the works of I.A. Miloslavova, L.M. Rostova, A.P. Rastigeev, L.L. Shpak, V.A. Spivak's, etc. (Reason, 2002).

The corporate culture acts as the difficult organizational phenomenon combining production, economic and social sides of corporate entrepreneurship, as well as the strategic implementation of the innovation capacity of this corporation reflecting the motivational mechanism.

The corporate innovation culture differs from the traditional culture of the companies, has the characteristic distinctive signs. So, most of the heads of the companies fear structural transformations, do not take the risk of new solutions that can lead to replacement of business from the market and potentially to bankruptcy. The innovation conceiving leader, on the contrary, aims at permanent changes, is inclined to entrepreneurial risk, forms round himself team of the conceiving, initiative professionals, creates the special environment promoting the innovation activity, the implementation of the creative potential of workers.

The established aspiration to the innovative development of corporate culture gives, really, boundless benefits of development, is a perennial spring of competitive activity of the company. Therefore, conscious forming of the innovation vector of development of corporate culture is paramount task which decision provides achievement, not only leader positions of the enterprise in the market, but also promotes achievement of satisfaction and stimulation of the personnel.

Appears super complex challenge of management of development of semi-structured complex system what the corporate culture is. The method of cognitive modelling is the most acceptable for the solution of such tasks (Tselikh, 2000).

For the purpose of formations of the innovation model of corporate culture identification of the factors, characteristics capable is necessary influence of the specific (characteristic) features corresponding to conditions of forming of culture at the level of separately taken organization, the industry (sector) of economy, the region of organization activity on dominant factors of its development is essential to influence necessary cultural shifts and promoting development of its innovation potential, and also.

The purpose of this work consists in, that on the basis of application of methodology of systems analysis and methods of comparative cognitive modeling to investigate essence and specifics of sale of the controlling mechanism the innovation capacity of corporation within its such objective organizational institute as "corporate culture" of the enterprises of the recreational sphere of Kabardino-Balkaria Republic.

This research is directed at the problem resolution of creation of tools of decision support for the purpose of implementation of policy and coordination of efforts on forming of the innovation potential of corporate culture on macro and micro-level based on interactions between cultures of the enterprises of regional recreational system.

This research is directed to the problem resolution of creation of tools for decision support for the purpose of implementation of policy and coordination of efforts on forming of the innovation potential of corporate culture on macro and micro level on the basis of interactions between cultures of the enterprises of the regional recreational system.

The novelty of the approach consists in synthesizing of a context of the innovation capacity of the organization, the innovation potential of corporate culture and national components (environments) of Kabardino-Balkaria Republic when developing models with the use of economic-mathematical tools of the methods of the comparative cognitive analysis of sales processes of the innovation potential of the corporate culture of the enterprises of the recreational sphere.

In the course of justification were used theoretical provisions, conclusions and recommendation tools of cognitive, economic-mathematical method, structurally functional, subject and object, economical and statistical, sociological and empirical methods of knowledge. 


\section{Modelling of Innovative Potential's Corporate Culture in Recreational Sector}

In order to identify a distinctive feature of the innovation potential of corporate culture were explained in three models:

- I model: innovative potential of the corporate culture of the tourism sector (excluding any special features);

- II model: innovative potential of the corporate culture of the tourism sector taking into account national environmental factors of KBR (national specifics);

- III model: innovative capacity of the organization recreational sphere.

In shaping patterns were accepted following assumptions:

1) Market environment;

2) Optional decision making about the choice of factor models

3) In one model is considered one target implementation

4) Concepts interact definitely among themselves (positively, negatively, does not interact);

5) Power of interaction between two concepts varies on the set scale

For creation of indistinct cognitive models (Maximov, 2001) the list of the concepts defining, forming and development of corporate culture (on the example of tourist sector of KBR) on the basis of 2000-2014 of scientific researches spent in the Russian Federation for the period in the field of corporate culture, and also foreign researches devoted to the analysis of interference and interrelation of corporate culture and the innovation capacity of the region, the industry, complex of the companies including small has been created.

The analysis and selection of factors considered such elements of corporate culture which are closely connected with steady innovation in development: the innovation mission and vision of the reporting, democratic communication, safe space, flexibility, cooperation, communications, motivation and leadership (Dombrowski \& et al., 2007; \& Ismail \& Abdmajid, 2007). Distinctive, positively connected with the capability to innovations in the small and medium enterprises, properties have noted such parties of corporate culture: collectivism and capability to innovations; expansion of the rights and opportunities for the personnel (Çakar \& Ertürk, 2010; \& Githii, www.iosrjournals.org, 2014). For the purpose of maintenance of the innovation potential the organizations need to pay attention to the factors characterizing knowledge management processes, the innovation and efficiency work having an essential impact on business development, survival, creation of competitive advantage (Janiunaite \& Petraite, 2010). Important aspects of culture of innovations are the tolerance for mistakes, support of the management, open communication, unity and recognition of work (Godoy \& Peçanha, 2009). The interrelation of organization culture and innovations from the point of view of the management theory demands a higher level of coordination between the purposes of management and the purposes of the organization, as a social system (Büschgens, Bausch \& Balkin, 2013). The efficiency of the innovation policy aimed at the development of "culture of steady innovations" in the basis depends on dynamic equilibrium of the history and culture of the region and continuous interaction with the external environment (Prud'homme van Reine Creating cultures of sustainable innovation, 2013) that predetermines need for the creation of a model taking into account factors national cultural region components.

Subject to the foregoing, 72 concepts, factors of the innovation potential of corporate culture grouped in blocks (table 1) are defined:

- declaration of mission, purpose, responsibility;

- corporate philosophy;

- leadership style and leadership;

- corporate management;

- corporate ethics;

- labor ethics and motivation;

- corporate image and reputation;

- culture of quality;

- characteristics of innovation of the system.

The systematic group of concepts was made also on the basis of the chosen model. 
Table 1 - Concepts of model of corporate culture

Concepts of model of corporate culture

№ Name of concepts

1 Development purposes of corporate culture

2 Declaring of social responsibility of the company: level

3 Organization mission: innovation directivity

4 Philosophy of social recognition of labor: the level of

5 Public mentality: the willingness to innovate, innovative thinking

6 Internationally recognized guidelines: non-discrimination, human rights, and equality

7 Social and psychological climate in the organization (playtime: sense of humor, a smile in communication between employees)

8 Consumerism

9 Co-ordination corporate purposes with development region objectives

10 The innovation environment - informal knowledge transfer: opportunity, space

11 Broadcast of response to difficult situations, crisis, conflict situations

12 Entrepreneurial leadership style: readiness in experimenting, risk

13 Innovative directions, priorities established leader in the distribution of resources

14 The manager used innovative direction of criteria to distribute rewards and status, strengthening of desirable behavior

15 Willingness to cooperate: the acceptability of "foreign" solutions

16 Team working principles

17 Transparency of decision-making at different levels (the principle of argumentation)

18 Democracy management system (collective participation in the governing bodies)

19 Development strategy: the innovation orientation

20 Morale: the level of conflict

21 Corporate communication standards

22 Adoption (preference) of new (creative) decisions earlier admitted to the organizations

23 Organization of knowledge transfer (presentation of the current and new projects)

24 Innovative communication basics: discussion platforms

25 The system of healthy competition: a sense of competition

26 Ethnic organization

27 Ethnic collectivism: activity, initiative

28 Socialization of the personnel

29 Tolerance to other nationalities: friendliness inherent in representatives of traditional societies

30 Ethical standards, characteristic of inhabitants of traditional societies: high moral values

31 Ethnic motivation

32 Level of self-esteem, general self-assessment

33 Influence of factor of the gender factor (role of the woman, attitude towards women, in general)

34 Multiethnic identity: communication in two languages - Russian and native

35 Special hospitality

36 Local culture and installations of the past

37 The celebration of national holidays

38 Ethnic and national features: communicativeness and sociability

39 Family traditions

40 Related relationships and their impact on the promotion of the career ladder

41 Confidence in the leadership

42 Personal culture

43 System of non-material stimulation (gratitude for well-done work, personal awards, etc.)

44 Innovative system of employee motivation

45 Policy staff selection system: conformism

46 Policy staff selection system: non-conformism

47 The principles of personnel selection: reliance on professionalism

48 The principles of personnel selection: reliance on loyalty, without professional competencies

49 Support system of innovation and invention: the level of development

50 Personnel policy focused on achieving the goals of social responsibility

51 Educations of the personnel: specialized in the tourism area

52 Awareness of the importance of own knowledge of the personnel for the organization

53 The system of coaching for young employees

54 The company's participation in the programs of social responsibility

55 Corporate symbolic

56 Long, stable, friendly relations with customers

57 Susceptibility of the system Kaizen costing and target costing: the adoption of the philosophy 


\begin{tabular}{|c|c|c|}
\hline Concepts of model of corporate culture & № $n$ & dele \\
\hline \begin{tabular}{|l|l|} 
№ & Name of concepts \\
\end{tabular} & II & III \\
\hline \begin{tabular}{|l|l|}
58 & Susceptibility of system of the general quality: adoption of philosophy \\
\end{tabular} & & \\
\hline \begin{tabular}{|l|l|}
59 & The acceptability, condemnation of colleagues for low-quality work \\
\end{tabular} & & \\
\hline \begin{tabular}{|l|l|}
60 & Ethnic discipline \\
\end{tabular} & & \\
\hline \begin{tabular}{|l|l|}
61 & Susceptibility of the personnel to innovations \\
\end{tabular} & & \\
\hline 62 Innovative activity of staff: level & & \\
\hline \begin{tabular}{|l|l|}
63 & Resistance to changes \\
\end{tabular} & & \\
\hline 64 learning environment & & \\
\hline \begin{tabular}{|l|l|}
65 & Rejection, non-acceptance of innovation management \\
\end{tabular} & & \\
\hline \begin{tabular}{|l|l|}
66 & Visualization of corporate culture: websites, social networks \\
\end{tabular} & & \\
\hline \begin{tabular}{|l|l|}
67 & The level of innovation for competitive advantage \\
\end{tabular} & & $\boldsymbol{\nabla}$ \\
\hline \begin{tabular}{|l|l|}
68 & Level of innovative development of new products \\
\end{tabular} & & $\nabla$ \\
\hline 69 Quality level of services (speed of customer service, relationship with the supplier and buyer) & & $\boldsymbol{\nabla}$ \\
\hline \begin{tabular}{|l|l|}
70 & Scientific and technical potential \\
\end{tabular} & & $\boldsymbol{\nabla}$ \\
\hline \begin{tabular}{|l|l|}
71 & Level of development of the open model of work culture \\
\end{tabular} & & $\nabla$ \\
\hline \begin{tabular}{|l|l|}
72 & Level of demand for soft employee competencies \\
\end{tabular} & & $\nabla$ \\
\hline
\end{tabular}

As the innovation potential on the basis is represented the accumulated knowledge expressed in new technologies, products, goods, services, respectively, its main carrier is the human capital, i.e. the personnel of the organization. Then it is possible to consider that such indicators as the level of the innovation activity and susceptibility of the personnel to innovations are the main (target) indicators of the innovation potential of corporate culture. All other factors promote their forming and growth / decrease.

We have defined the following standard lines of factors:

- obligation/desirability;

- direct/indirect influence;

- demand / does not demand the certain conditions, operating at the same time factors (catalysts);

- the target / managing.

For example, we will consider indicator "The level of formation / development of the innovation environment". Certainly, this factor is necessary and forms base (basis) of forming of the innovation capital. Its task - to promote, help development of the innovation activity of workers, to create for this purpose necessary infrastructure, favorable, friendly space for the emergence of ideas and implementation of innovations. However, if there is high innovation activity of the personnel, even without an availability of the environment, the innovation potential can form. Of course, its forming will take place in more difficult conditions and not such rates as could be, but, nevertheless, absence/availability of this factor is not obligatory. Such factor is desirable but is not obligatory.

Let's show a bit different approach to reasoning's in relation to another factor - "The principles of selection of the personnel: with support for professionalism". This factor is also not directly connected with forming of the innovation potential. At the implementation of such HR policy the group of professionally trained, well knowing the work, competent specialists is provided. But to tell that it will provide the innovation development, it would be incorrect as some more traits of character of the person, at least, availability of the creative beginning, initiative, etc. for this purpose are required. The collective from lacking initiative, not creative people is not capable to create the innovation product. Availability of this factor, unlike considered above, cannot be ignored since the carrier of the innovation capital are people, and providing collective with certain key data is necessary for the achievement of the innovation purposes. Therefore, this factor is obligatory, but not direct and demanding the supporting efforts, factors catalysts.

Similar reasoning's have formed the basis of the establishment of communications between factors. Forming of the relations between factors concepts of indistinct cognitive map is made with the use of the method of paired comparison.

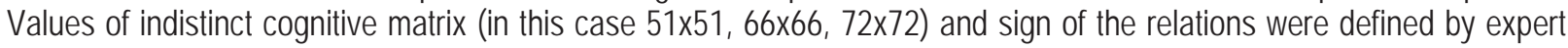
method. The choice of values was made by experts on the basis of triangular indistinct numbers (Table. 2). 
Table 2 - Values of the intensity of relations between concepts

\begin{tabular}{|l|l|l|c|}
\hline \multicolumn{3}{|c|}{ Interpretation of intensity of influence of concept of ei on ej } & \multirow{2}{*}{ Interval of values } \\
\hline \multirow{2}{*}{$\begin{array}{l}\text { Linguistic description of extent of } \\
\text { influence }\end{array}$} & Vector of influence & $\begin{array}{l}\text { Description of intensity of influence and related triangular } \\
\text { indistinct numbers }\end{array}$ & {$[0,0,2,0,4]$} \\
\hline \multirow{2}{*}{ Minimum } & Strengthens & influences weak positively & {$[-0,4,-0,2,0]$} \\
\cline { 2 - 4 } & Weakens & influences poorly in negative key: & {$[0,2,0,4,0,6]$} \\
\hline \multirow{2}{*}{ Poor } & Strengthens & influences weak moderately positively: & {$[-0,4,-0,2,0]$} \\
\cline { 2 - 4 } & Weakens & influences poorly in negative key & {$[0,4,0,6,0.8]$} \\
\hline \multirow{2}{*}{ Conservative } & Strengthens & influences moderately positively & {$[-0,6,-0,4,-0,2]$} \\
\cline { 2 - 4 } & Weakens & influences weak moderately negatively & {$[0,6,0,8,1]$} \\
\hline \multirow{2}{*}{ Powerful } & Strengthens & influences moderate strongly in positive side & {$[-1,-0,8,-0,6]$} \\
\cline { 2 - 4 } & Weakens & influences moderate strongly in negative key & {$[0,8,1,1]$} \\
\hline \multirow{2}{*}{ Maximum } & Strengthens & influences strongly in positive side & {$[-1,-1,0]$} \\
\cline { 2 - 4 } & Weakens & influences strongly in negative key & {$[-0,2,0,0,2]$} \\
\hline None & & does not influence all & \\
\hline
\end{tabular}

Constructed cognitive models have the form of a weighted directed graph, whose vertices correspond to the factors (the set E), and the arcs represent causal relationships between factors (the set of W). Weighted directed graph reflects average (according to expert analysis) communication concepts and values of the model influence the innovative capacity of the corporate culture. Relationship of cause and effect relationships are expressed in cognitive matrix is the adjacency matrix (the set of W). Mathematical treatment of cognitive maps produced using the software DSS "needle" (Decision Support System), developed by the research team of the Department "Computer Science and Software" Bryansk State Technical University under the guidance of D.A. Korostelyova.

Statement of the problem. The generated models allow for a consistent analysis of the cognitive factors of corporate culture of innovation potential of the tourism sector of the Kabardino-Balkaria Republic.

Background:

1. Objectives of cognitive analysis:

- To establish the most important factors of corporate culture in the tourism sector (in terms of the application of control action), creating its innovative potential (without specific features);

- Assess the impact of national environmental factors (national characteristics) on the innovative potential of the corporate culture of the tourism sector of the CBD;

- To establish the most important factors of corporate culture, influencing the innovation potential of the tourism sector of the CBD;

- A comparative analysis of vector effects.

2. The object of study: enterprises of recreational sphere of the CBD.

3. When solving the tasks, methods of system analysis, theory of cognitive modeling, graph theory, fuzzy logic, simulation, computer-aided graphic design, analytical groups, and expert analysis.

4. Assumptions:

- Evaluation of reliability of the findings in the model is carried out using the mechanism for calculating cognitive consonance / dissonance, taking into account the net result of all bonds, provided that other causes are small.

\section{Conclusion}

Analyzing the initial conditions for the occurrence of innovative potential of corporate culture enterprises of recreational sphere of Kabardino - Balkaria Republic on the basis of comparative cognitive modeling can draw the following conclusions:

1. Market innovation potential of enterprises in the tourism sector of the Kabardino - Balkaria Republic depends on three economic vectors - the market of internal institutional framework of the Tourism Organization (model № I), market organization external institutional framework of corporate microeconomics (model № II) and market organization of corporate macroeconomics ( model № III). With this market principles of organization and functioning of innovative potential corporation it can detect the maximum effectiveness of their investment, industrial, technological and economic opportunities.

2. Presentation models №№ - I, II, III shows the development of the corporation in three capacities: as an object 
of organizational and institutional impact - model № I (since it takes over the corporate culture of previous generations), as a subject of management culture - a model № II (r. to. be included in the process of establishing corporate standards), and as an institutional carrier of corporate culture - the model № III.

Thus, the comparative analysis shows cognitive cognitive-evolutionary aspect of the formation of the innovative capacity of a corporate culture based on the boundaries of time and space (the innovative capacity of the organization), allows you to get a better idea about the design of the system (a set of concepts, factors) to achieve the goal of innovative development.

\section{References}

Maximov, V.I., 2001. Cognitive analysis and modeling of difficult situations / V. I. Maximov, E.K. Kornoushenko, S. V. Kachayev//Banking technologies. No. 7. pp 21-26.

Reason, O.S., 2002. Problems of market transformation of the innovation capacity of corporation//Finance and credit. - M.: JSC Izd. dom Finansy and credit. No. 7. pp. 14-19.

Tselikh, A.N., 2000. Development and research of models of decision making in the integrated intellectual systems and their application for the solution of ecological tasks: yew. ... Dr.Sci.Tech.: 05.13.14, 05.13.16. Taganrog.

Büschgens T., Bausch A. \& Balkin D.B., 2013. Organizational Culture and Innovation: A Meta-Analytic Review/l Journal of Product Innovation Management, V.30, iss.4, pp. 763-781.

Çakar, N.D. \& Ertürk A., 2010. Comparing innovation capability of small and medium-sized enterprises: Examining the effects of organizational culture and empowerment. Journal of Small Business Management, 48(3), pp. 325-359.

Dombrowski, C., Kim J.Y., Desouza K.C., Brabanza A., Papagari S., Baloh, P. \& Jha S., 2007. Elements of innovative cultures. Knowledge and Process Management, 14(3), 190-202.

Githii, S.K., 2014. Knowledge management practices and innovation performance: a literature review/l IOSR Journal of Business and Management (IOSR-JBM). Volume 16, Issue 2. Ver. I, pp. 89-94, URL: www.iosrjournals.org.

Godoy, R.S.P. \& Peçanha D.L.N., 2009. Cultura organizacional e processos de inovação: um estudo psicossociólogico em empresa de base tecnológica. Boletim Academia Paulista de Psicologia, 29(1), pp. 142-163.

Ismail, W.K.W. \& Abdmajid R., 2007. Framework of the culture of innovation: A revisit. Jurnal Kemanusiaan, 9, pp. 38-49.

Janiunaite, B., \& Petraite M., 2010. The relationship between organizational innovative culture and knowledge sharing in organization: The case of technological innovation implementation in a telecommunication organization. Socialiniai Mokslai, 3(69), pp. 14-23.

Prud'homme van Reine Creating cultures of sustainable innovation, 2013. Journal of Innovation Management (JIM) 1, 1. pp. 85-107. 
ISSN 2039-2117 (online) ISSN 2039-9340 (print)
Mediterranean Journal of Social Sciences MCSER Publishing, Rome-Italy
Vol 6 No 3 S4 May 2015 